IGUSABDER, 10 (2020): 64-76

\title{
İç Hastalıkları Kliniğine Yatışı Yapılan Diyabetes Mellitüs Tanılı Hastaların Birimlerine Göre Maliyet Analizi*
}

\author{
Ömer ŞEKER ${ }^{* *}$, Mehmet KÖROĞLU***, Yıldız OKUTURLAR ${ }^{* * * *}$
}

$\ddot{O} \mathbf{z}$

Amaç: Gelişmiş ülkelerde Diyabetes Mellitüs (DM) tanılı hastaların yıllık giderleri değerlendirildiğinde giderlerin hastane yatışı ve tedaviler, komplikasyonların tedavisi, antidiyabetik ilaçlar ve ajanlar, doktor ziyaret ücretleri, hemşirelik ve bakım hizmetleri ve acil servis başvuruları için harcandığı görülmüştür. Bu çalışmada İç Hastalıkları kliniğine yatırılan hastaların maliyet analizleri planlanlanmıştır.

Yöntem: Bu çalışmada 01.01.2011-30.09.2014 tarihleri arasında İç Hastalıkları kliniğine yatırılan Tip 1 ve Tip 2 DM tanısı alan hastalar bilgisayar verilerinden taranmıştır. Hastaların yaş, cinsiyet, yatış süreleri, yıllara göre yatış dağılımı, kaç kez yattıkları, sosyal güvenceleri, toplam yatış maliyetleri ve birimlere göre yatış maliyetleri gruplandırılarak kaydedilmiştir.

Bulgular: Diyabet tanılı hastaların yıllık giderlerini araştıran birçok çalışma ile birlikte bu çalışma değerlendirdiğimizde giderler içerisinde ilaç harcamalarının ve laboratuvar tetkiklerinin yanı sıra komplikasyonların tanısı ve tedavisinin de önemli yer tuttuğunu tespit edilmiştir. Çalışmada medikal tedavilerin, laboratuvar analizlerinin, yatak ücretlerinin yanında hemodiyaliz giderlerinin ön planda olması beklenildiği gibi hasta grubunda renal komplikasyonların sık görülmesiyle açıklanabilir. Bu çalışma, yurtdışındaki benzer çalışmalarla karşılaştırıldığında hekim vizitlerinin maliyete katkısının oldukça düşük olduğunu saptanmıştır.

\footnotetext{
Özgün Araştırma Makalesi (Original Research Article )

Geliş/Received: 22.01.2020 \& Kabul/Accepted: 03.02.2020

${ }^{*}$ Bu makale, Dr. Yıldız OKUTURLAR danışmanlığında hazırlanan ve Bakırköy Dr. Sadi Konuk Eğitim ve Araştırma Hastanesi’nde 2015 yllında kabul edilen “2011-2014 Yllları Arasında Bakırköy Dr. Sadi Konuk Eğitim ve Araştırma Hastanesi İç Hastalıkları Kliniği’ne Yatışı Yapılan Hastaların Birimlere Göre Maliyet Analizi” başlıklı uzmanlık tez çalışmasından üretilmiştir. *** Uzm. Dr., Mardin Devlet Hastanesi, Mardin, Türkiye, E-posta: bensheker@hotmail.com, ORCIID IID https://orcid.org/0000-0002-0801-877X

*** Dr. Öğr. Üyesi, İstanbul Gelişim Üniversitesi, Sağlık Bilimleri Yüksekokulu, İstanbul, Türkiye, E-posta: smkoroglu@hotmail.com, ORCIID IID https://orcid.org/o0oo-0002-1192-4159

***** Doç. Dr., Acıbadem Üniversitesi, Tıp Fakültesi, İstanbul, Türkiye,

E-posta: y.okuturlar@gmail.com ORCID IID https://orcid.org/o000-0002-1994-0014
} 
Sonuç: Tüm elde edilen veriler göz önüne alındığında; giderek daha önemli bir sağlık problemi olan Diyabetes Mellitüs tedavisinde daha başarılı olmak ve maliyeti düşürebilmek amacıyla hastaların hastalık ve komplikasyonları hakkında detaylı bilgilendirilmesinin ve düzenli aralıklarla doktor tarafından takip edilmesinin önemli olduğu kanaatine varılmıştır.

Anahtar Sözcükler: Tip 1 diyabet, tip 2 diyabet, maliyet analizi.

\title{
Cost Analysis of Hospitalized Diabetic Patients in Internal Medicine Service
}

\begin{abstract}
Aim: In this study, we investigated unit cost analysis of hospitalized diabetic patients, the distribution of hospitalizations according to years and the total hospitalization costs.

Method: In this study the hospitalized patients with type 1 diabetes and type 2 diabetes between the date 01.01.2011 and 30.09.2014 were retrospectively reviewed. Age, sex, length of hospitalization, distribution of hospitalizations by years, number of hospitalizations, social security, total hospitalization costs and hospitalization costs by units were grouped.
\end{abstract}

Findings: Considering many studies investigating the annual costs of patients diagnosed with diabetes and our study, we determined that in addition to the medical expenses and laboratory examinations, the diagnosis and treatment of complications have an important place in the expenses. The prominence of the hemodialysis costs comparing with the laboratory costs and medical treatment costs can be explained by the renal complications that were seen mostly in our patients. Again, when we compared our study with similar studies from other countries, we found that the contribution of physician visits to the cost was quite low.

Conclusion: Considering all the data we have obtained; we can see that, patient information, preventive medicine and patient care services are not enough in our country. We think that both the regular doctor visits and informing the patients about complications are very important to lower the costs and to become successful in the treatment of diabetes mellitus which is an increasingly important health problem.

Keywords: Type 1 diabetes, type 2 diabetes, cost analysis.

\section{Giriş}

Maliyet çalışmaları sağlık hizmetlerinin daha verimli ve etkin olarak topluma sunulması için gereklidir. Hastalığın topluma getireceği ekonomik yükü gösteren çalışmalar, hastalık maliyeti (cost of illness) olarak isimlendirilir ${ }^{1}$. 
Ülkemizde genel olarak maliyet analizlerini içeren çalışmalar az sayıdadır²,3. Hastalık maliyetleri; hastalığın tanı işlemlerine ait harcamalar, ilaç harcamaları, hastalığın takibiyle ilgili giderler, poliklinik ve hastane yatışlarını ve tedavi giderlerini içeren doğrudan sağlık harcamaları ve hastalığa bağlı iş gücü kaybının yol açtığı dolaylı sağlık harcamaları olarak iki ayrı sınıfta değerlendirilir. Doğrudan sağlık harcamaları içerisinde; hastalığın tanı işlemlerine ait harcamalar, ilaç harcamaları, hastalığın poliklinik takibiyle ilgili giderler ve hastane yatış maliyetleri yer alır. Dolaylı maliyet ölçümleri ise aktivite kısıtlanması, maluliyet ve erken ölüme bağlı işgücü ve üretim kayıplarını kapsamaktadır ${ }^{4}$.

2013 yılında yayınlanan Türkiye Diyabet, Hipertansiyon, Obezite ve Endokrinolojik Hastalıklar Prevalans Çalışması-II (TURDEP-II)'ye göre Türk erişkin toplumunda diyabet sıklı̆̆ının \%13,7’ye ulaştığı görülmüştür. Dünya Sağlık Örgütüne göre tüm dünyada 347 milyon Diyabetes Mellitüs tanılı hasta mevcuttur. Diyabet yol açtı̆̆ komplikasyonlar açısından zengin bir hastalıktır. Diyabetin inme (stroke), koroner arter hastalı̆̆ı, böbrek yetersizliği, körlük, nöropati, periferik arter hastalı̆̆ı gibi önemli kronik komplikasyonları mevcuttur 5 .

Bu çalışmada, 2011-2014 yılları arasında diyabet tanısı olan ve Bakırköy Dr. Sadi Konuk Ĕ̆itim ve Araştırma Hastanesi İç Hastalıkları Kliniği’ne yatırılan hastalar retrospektif olarak değerlendirilmiş, hastalık maliyet analizi yapmak amaçlanmıştır.

\section{Gereç ve Yöntem}

Bu çalışmada 01.01.2011-30.09.2014 tarihleri arasında Tip 1 ve Tip 2 diyabet tanısı alan hastaların dosyaları bilgisayar verileri kullanılarak kaydedilmiştir. Hastaların yatış nedenleri arasında enfektif hastalıklar, akut, kronik ve son dönem böbrek yetersizliği, kalp yetersizliği, akut pankreatit, malignite şüphesi nedeniyle ileri tetkik, akciğer hastalıklarına bağlı solunum yetersizliği, anemi etyolojisinin araştırılması, diyabete bağlı gelişen komplikasyonların tedavisi gibi birçok neden mevcuttu. Hastaların yaş, cinsiyet, yatış süreleri, yıllara göre yatış dağılımı, kaç kez yattıkları, sosyal güvenceleri ve yatış maliyetleri gruplandırılarak (anestezi, anjiografik tetkikler, bilgisayarlı tomografi, biyokimyasal tetkikler, dahiliye servis ambarı (bu başlık altında IV kanül, enjektör, maske, foley sonda, oksijen maskesi, nazal kanül, idrar torbası, damla ayarlayıcısı, aspirasyon sondası ve torbası gibi gibi ilaç içermeyen hizmetler girilmiştir), 
eczane, endoskopi ünitesi, ekokardiyografi, genel ve girişimsel radyoloji işlemleri, göz ve adneksleri, hematoloji- onkoloji- kemoterapi, hemodiyaliz, kan bankası, kültür laboratuvarı, mammografi, manyetik rezonans görüntülemeleri, mikrobiyoloji laboratuvarı, muayene ücretleri, patolojik incelemeler, radyoloji direkt grafileri, rapor ücretlendirmeleri, refakat ücretleri, renkli doppler ve diğer ultrasonografik incelemeleri, yatak ücretleri) kaydedilmiştir. Hastaların maliyetleri, T.C. Merkez Bankası verileri baz alınarak 2011-2014 yılları arası ortalama Amerikan Dolar Kuru ( $\$ 1=1,8073 \mathrm{Tl})$ üzerinden de belirtilmiştir.

İstatistiksel analizler için Number Cruncher Statistical System 2007 (NCSS 2007) (Kaysville, Utah, USA) programı kullanılmıştır. Çalışma verileri değerlendirilirken tanımlayıcı istatistiksel metotların (ortalama, standart sapma, medyan, frekans, oran, minimum, maksimum) yanı sıra niceliksel verilerin karşılaştırılmasında normal dağılım göstermeyen parametrelerin iki grup karşılaştırmalarında Mann Whitney U testi kullanılmıştır. Anlamlılık p<0,01 ve p<0,05 düzeylerinde değerlendirilmiştir.

\section{Bulgular}

Bu çalışma, 2011-2014 tarihleri arasında Bakırköy Dr. Sadi Konuk Eğitim Araştırma Hastanesi İç Hastalıkları Kliniği’nde \%52,2'si (n=421) kadın, \%47,8’i (n=386) erkek olmak üzere toplam 807 olgu ile yapılmıştır. Çalışmaya katılanların yaşları 15,7 ile 101,7 yıl arasında değişmekte olup, ortalama 65,5土15,7 yıldır; \%44,o’ü (n=355) 65 yaşın altında, \%56,o'sı $(n=452) 65$ yaş ve üzerindedir. Hastaların demografik özellikleri ve tanımlayıcı özelliklerinin dağılımı Tablo 1'de verilmiştir.

Tablo 1: Tanımlayıcı özelliklerin dağılımı

\begin{tabular}{llll}
\hline & & Min-Mak (Medyan) & Ort \pm SS \\
\hline Yaş (yıl) & & $15,7-101,7(67,2)$ & $65,5 \pm 15,7$ \\
Yatış sayısı & $1-19(1)$ & $1,8 \pm 1,9$ \\
\hline & & $\mathbf{n}$ & $\mathbf{\%}$ \\
\hline Yaş (yıl) & $<65$ yaş & 355 & 44,0 \\
& $\geq 65$ yaş & 452 & 56,0 \\
Cinsiyet & Kadın & 421 & 52,2 \\
& Erkek & 386 & 47,8 \\
Yatış sayısı & 1 yatış & 544 & 67,4 \\
& 2 yatış & 138 & 17,1 \\
& $\geq 3$ yatış & 125 & 15,5 \\
\hline
\end{tabular}


Maliyet analizine göre 27 birime ayrılan hastalarda ortalama maliyette en fazla yer alan birimler içerisinde sırasıyla; eczane (hastaların \%95,9) 248,8 $\pm 487,6$ TL, biyokimya laboratuvarı (hastaların \%99,5) 247,3 $\pm 174,0$ TL, yatak ücreti (hastaların \% 95,4) $211,7 \pm 179,8 \mathrm{TL}$, hemodiyaliz (hastaları \% 24,7) 123,2 $\pm 280,6 \mathrm{TL}$, genel müdahaleler (hastaların \% 96) 98,8 $\pm 123,7$ TL olarak tespit edilmiştir. Toplam maliyet ve alt birimlere ilişkin dağılımlar Tablo 2 ve Tablo 3 ’te verilmiştir.

Tablo 2: Toplam Maliyet ve Alt Birimlere İlişkin Dağılımlar

\begin{tabular}{|c|c|c|c|}
\hline \multirow[t]{2}{*}{$\mathbf{n}=\mathbf{8 0 7}$} & \multicolumn{3}{|c|}{ Maliyet (TL) } \\
\hline & Min-Mak & Ort \pm SS & Medyan \\
\hline Toplam maliyet & $31,5^{-18.606,3}$ & $1.269,8 \pm 1.332,0$ & 889,4 \\
\hline Anestezi & $0-270,1$ & $11,4 \pm 35,8$ & o \\
\hline Anjiografik tetkikler & $0-251,8$ & $0,9 \pm 13,2$ & o \\
\hline Biyokimya laboratuvarı & $0-1.758,2$ & $247,3 \pm 174,0$ & 215,3 \\
\hline Bilgisayarlı tomografi & $0-242,0$ & $16,2 \pm 40,9$ & o \\
\hline Dahiliye servis ambarı & $0-449,5$ & $32,2 \pm 53,3$ & 12,6 \\
\hline Endoskopi & $0-2.380,4$ & $4,7 \pm 86,8$ & o \\
\hline Ekokardiyografi & $0-120,3$ & $4,6 \pm 12,5$ & o \\
\hline Eczane & $0-10.595,9$ & $248,8 \pm 487,6$ & 133,5 \\
\hline Göz ve adneksleri & $0-127,6$ & $0,5 \pm 6,9$ & o \\
\hline Girişimsel radyoloji ambarı & $0-5 \cdot 113,4$ & $12,8 \pm 188,9$ & o \\
\hline Genel müdahaleler & $0-1.941,6$ & $98,8 \pm 123,7$ & 62,6 \\
\hline Hematoloji-onkoloji-kemoterapi & $0-4.998,8$ & $66,8 \pm 284,8$ & o \\
\hline Kültür laboratuvarı & $0-225,2$ & $8,0 \pm 20,4$ & o \\
\hline Kardiyovasküler sistem & $0-176,0$ & $1,1 \pm 9,9$ & o \\
\hline Kardiyoloji lab. ambarı & $0-193,3$ & $0,3 \pm 7,3$ & o \\
\hline Patoloji & o-933,7 & $24,2 \pm 100,9$ & o \\
\hline Rapor ücretleri & $0-2,2$ & $0,3 \pm 0,5$ & o \\
\hline Radyoloji direkt grafiler & $0-120,2$ & $6,2 \pm 11,5$ & o \\
\hline Refakat ücretleri & $0-250,0$ & $31,5 \pm 37,7$ & 20,0 \\
\hline Renkli doppler ultrasonografi & $0-186,6$ & $3,0 \pm 15,8$ & o \\
\hline Muayene ücretleri & $0-120,0$ & $5,8 \pm 10,8$ & o \\
\hline Mikrobiyoloji laboratuvarı & $0-1.130,8$ & $74,1 \pm 97,2$ & 54,0 \\
\hline Solunum sistemi & $0-81,3$ & $0,2 \pm 3,6$ & o \\
\hline Sindirim sistemi & $0-636,9$ & $9,6 \pm 46,4$ & o \\
\hline Ultrasonografi & $0-190,4$ & $7,9 \pm 13,9$ & o \\
\hline Hemodiyaliz & $0-1.975,8$ & $123,2 \pm 280,6$ & o \\
\hline Yatak ücretleri & $0-1.680$ & $201,97 \pm 181,12$ & 150 \\
\hline
\end{tabular}




\begin{tabular}{|c|c|c|c|c|c|}
\hline \multicolumn{6}{|c|}{ Tablo 3: Alt Birimlere Göre Maliyet Dağılımları } \\
\hline & \multirow[b]{2}{*}{ n (\%) } & \multicolumn{2}{|c|}{ Kişi Başına Düşen Maliyet (TL) } & \multicolumn{2}{|c|}{ Toplam Maliyet (TL) } \\
\hline & & Min- Mak (medyan) & Ort \pm SS & Ort \pm SS & Medyan \\
\hline Anestezi & $115(14,3)$ & $0,9-270,1(59,4)$ & $79,8 \pm 59,5$ & $1.952,3 \pm 1.425,3$ & $1.552,6$ \\
\hline Anjiografik tetkikler & $5(0,6)$ & $55,9-251,8(177,2)$ & $149,2 \pm 85,4$ & $4.231,4 \pm 2.355,4$ & $3.412,5$ \\
\hline Biyokimya & $803(99,5)$ & $3,3-1.758,2(215,6)$ & $248,5 \pm 173,5$ & $1.275,6 \pm 1.332,7$ & 891,5 \\
\hline laboratuvarı & & & & & \\
\hline Bilgisayarlı tomografi & $133(16,5)$ & $60,5-242,0(82,0)$ & $98,6 \pm 45,8$ & $2.382,0 \pm 2.198,0$ & $1.797,8$ \\
\hline Dahiliye servis ambarı & $610(75,6)$ & $0,23-449,5(20,9)$ & $42,6 \pm 57,5$ & $1.507,5 \pm 1.423,1$ & $1.093,4$ \\
\hline Endoskopi & $46(5,7)$ & $0,02-2 \cdot 380,3(1,9)$ & $82,2 \pm 358,3$ & $2.710,4 \pm 1.575,6$ & $2.371,5$ \\
\hline Ekokardiyografi & $116(14,4)$ & $26,2-120,3(28,8)$ & $32,32 \pm 14,1$ & $1.938,9 \pm 1.292,6$ & $1.576,8$ \\
\hline Eczane & $774(95,9)$ & $0,71-10.595,8(141,7)$ & $259,5 \pm 495,1$ & $1.307,1 \pm 1.346,4$ & 934,1 \\
\hline Göz ve adneksleri & $4(0,5)$ & $59,6-127,6(93,5)$ & $93,6 \pm 34,7$ & $2.142,4 \pm 1.566,6$ & $1.771,2$ \\
\hline $\begin{array}{l}\text { Girişimsel radyoloji } \\
\text { ambarı }\end{array}$ & $33(4,1)$ & $1,92-5.113,4(103,2)$ & $312,4 \pm 895,7$ & $2.026,4 \pm 1.860,8$ & $1.227,3$ \\
\hline Genel müdahaleler & $777(96,3)$ & $1,8-1.941,6(66,3)$ & $102,6 \pm 124,5$ & $1.303,7 \pm 1.344,7$ & 929,9 \\
\hline $\begin{array}{l}\text { Hematoloji-onkoloji- } \\
\text { kemoterapi }\end{array}$ & $180(22,3)$ & $5,1-4.998,8(186,4)$ & $299,3 \pm 543,3$ & $2.333,6 \pm 2.065,1$ & $1.667,1$ \\
\hline Kültürr laboratuvarı & $306(37,9)$ & $1,1-225,2(9,35)$ & $21,1 \pm 28,7$ & $1.940,9 \pm 1.734,5$ & $1.499,3$ \\
\hline $\begin{array}{l}\text { Kardiyovasküler } \\
\text { sistem }\end{array}$ & $19(2,4)$ & $29,7-1.76,0(29,7)$ & $46,7 \pm 46,1$ & $1.343,6 \pm 762,9$ & $1.207,8$ \\
\hline $\begin{array}{l}\text { Kardiyoloji lab. } \\
\text { ambarı }\end{array}$ & $2(0,2)$ & $77,13-193,3(135,2)$ & $135,2 \pm 82,2$ & $1.853,7 \pm 907,5$ & $1.853,7$ \\
\hline Rapor ücretleri & $76(21,8)$ & $1,1-2,2(1,1)$ & $1,2 \pm 0,3$ & $1.492,9 \pm 1.271,1$ & $1.064,1$ \\
\hline $\begin{array}{l}\text { Radyoloji direkt } \\
\text { grafiler }\end{array}$ & $366(45,4)$ & $7,48-120,3(7,48)$ & $13,8 \pm 13,7$ & $1.791,9 \pm 1.659,8$ & $1.352,5$ \\
\hline Refakat ücretleri & $483(59,9)$ & $10-250,0(40)$ & $52,7 \pm 35,6$ & $1.608,3 \pm 1.503,3$ & 1.184 \\
\hline Renkli doppler usg & $45(5,6)$ & $23,32-186,6(46,6)$ & $52,8 \pm 43,4$ & $2.597,3 \pm 2.981,9$ & $2.025,9$ \\
\hline Muayene ücretleri & $349(43,2)$ & $6-120,0(6)$ & $13,3 \pm 13,1$ & $1.858,2 \pm 1.702,6$ & $1.376,2$ \\
\hline Mikrobiyoloji & $741(91,8)$ & $2,75^{-1.130,8}(56,2)$ & $80,8 \pm 98,8$ & $1.356,3 \pm 1.355,1$ & 995,3 \\
\hline laboratuvarı & & & & & \\
\hline Solunum sistemi & $4(0,5)$ & $25-81,32(37,5)$ & $45,3 \pm 26,7$ & $1.543,3 \pm 723,4$ & $1.427,2$ \\
\hline Sindirim sistemi & $52(6,4)$ & $62,6-636,9(74,7)$ & $149,0 \pm 113,5$ & $2.589,5 \pm 1.541,9$ & $2.280,2$ \\
\hline Ultrasonografi & $257(31,8)$ & $11,2-190,4(26,18)$ & $24,7 \pm 13,9$ & $1.771,7 \pm 1.416,0$ & $1.362,6$ \\
\hline Hemodiyaliz & $199(24,7)$ & $3,6-1.975,8(410,26)$ & $499,5 \pm 362,7$ & $2.032,7 \pm 1.234,3$ & $1.612,7$ \\
\hline Yatak ücretleri & $770(95,4)$ & 6,o-1.680,o (180) & $211,7 \pm 179,8$ & $1.306,0 \pm 1.349,3$ & 926,7 \\
\hline
\end{tabular}

Yaş gruplarına göre olguların toplam maliyetleri arasında istatistiksel olarak ileri düzeyde anlamlı farklılık saptanmıştır ( $\mathrm{p}=0.001, \mathrm{p}<0.01)$; 65 yaş ve üzerindeki olguların toplam maliyet düzeyi, 65 yaşın altındaki olgulardan anlamlı düzeyde yüksektir (Tablo 4). 
Tablo 4: Yaşa Göre Toplam Maliyetin Değerlendirilmesi

\begin{tabular}{|c|c|c|c|}
\hline & & (yil) & \\
\hline & $<65$ yaş $(n=355)$ & $\geq 65$ yaş $(n=452)$ & \\
\hline & Ort \pm SS (Medyan) & Ort \pm SS (Medyan) & $\boldsymbol{p}$ \\
\hline Tonlam Malivet (TL) & $1.148,4 \pm 1.173,6(764,4)$ & $1.365,2 \pm 1.438,3(1006,8)$ & $0001^{* *}$ \\
\hline & {$[\$ 637,8]$} & {$\left[\$ 75^{8}, 4\right]$} & 0,001 \\
\hline
\end{tabular}

Cinsiyete göre olguların toplam maliyetleri arasında karşılaştırma yapıldığında istatistiksel olarak anlamlı farklılık saptanmamıştır ( $>0,05$ ) (Tablo 5).

Tablo 5: Cinsiyete Göre Toplam Maliyetin Değerlendirilmesi

\begin{tabular}{llll}
\hline & & Cinsiyet & \\
& Kadın $(\mathbf{n}=\mathbf{4 2 1})$ & Erkek $(\mathbf{n}=\mathbf{3 8 6})$ & \\
& Ort \pm SS (Medyan) & Ort \pm SS (Medyan) & $\boldsymbol{p}$ \\
\hline \multirow{2}{*}{ Toplam Maliyet (TL) } & $1.235,5 \pm 1.226,7(838)$ & $1.307,2 \pm 1.438,7(926,6)$ & \multirow{2}{*}{, 419} \\
& {$[\$ 686,3]$} & {$[\$ 726,1]$} & \\
\hline
\end{tabular}

Mann Whitney U Test

Cinsiyet ve yaşa göre toplam maliyetlerin değerlendirilmesi yapıldığında; kadın olgulardan 65 yaş ve üzerinde olanların toplam maliyet düzeylerinin, 65 yaşın altındaki olgulardan yüksek olması istatistiksel olarak anlamlı bulunmuştur ( $\mathrm{p}=0,007 ; \mathrm{p}<0,01)$. Ayrıca; erkek olgulardan 65 yaş ve üzerinde olanların toplam maliyet düzeylerinin, 65 yaşın altındaki olgulardan yüksek olması da istatistiksel olarak anlamlı bulunmuştur $(\mathrm{p}=0.005 ; \mathrm{p}<0.01)$ (Tablo 6). 
Tablo 6: Cinsiyet ve Yaşa Göre Toplam Maliyetin Değerlendirilmesi

\begin{tabular}{|c|c|c|c|c|c|c|}
\hline & Ka & Inn & & & cek & \\
\hline & $\begin{array}{l}<65 \text { yaş } \\
(n=166)\end{array}$ & $\begin{array}{l}\geq 65 \text { yaş } \\
(n=255)\end{array}$ & & $\begin{array}{l}<65 \text { yaş } \\
(n=189)\end{array}$ & $\begin{array}{l}\geq 65 \text { yaş } \\
(n=197)\end{array}$ & \\
\hline & $\begin{array}{l}\text { Ort } \pm \text { SS } \\
\text { (Medyan) }\end{array}$ & $\begin{array}{l}\text { Ort } \pm \text { SS } \\
\text { (Medyan) }\end{array}$ & $p$ & $\begin{array}{l}\text { Ort } \pm \text { SS } \\
\text { (Medyan) }\end{array}$ & $\begin{array}{l}\text { Ort } \pm \text { SS } \\
\text { (Medyan) }\end{array}$ & $\boldsymbol{p}$ \\
\hline $\begin{array}{l}\text { Toplam } \\
\text { Maliyet }\end{array}$ & $\begin{array}{l}1.099,6 \pm 1.148,0 \\
(749,7)\end{array}$ & $\begin{array}{l}1.324,0 \pm 1.269,6 \\
(1006,9)\end{array}$ & $\boldsymbol{o}, \boldsymbol{0 0} 7^{* *}$ & $\begin{array}{l}1.191,3 \pm 1.197,0 \\
(766,6)\end{array}$ & $\begin{array}{l}1.418,5 \pm 1.632,9 \\
(1006,6)\end{array}$ & $0,005^{* *}$ \\
\hline (TL) & {$[\$ 610,5]$} & & & {$[\$ 661,8]$} & {$[\$ 788,0]$} & \\
\hline
\end{tabular}

Mann Whitney UTest $\quad{ }^{* *} p<0.01$

Yaşa göre birimlere ilişkin maliyetin değerlendirilmesi yapıldı̆̆ında; olgulardan 65 yaş ve üzerindeki olguların biyokimya laboratuvarı $(p=0,004)$, eczane $(p=0,001)$, genel müdahaleler ( $\mathrm{p}=0,001)$, hematoloji- onkoloji- kemoterapi $(\mathrm{p}=0,015)$, refakat ücretleri $(\mathrm{p}=0,009)$ ve yatak ücretleri $(\mathrm{p}=0,033)$ maliyetlerinin, 65 yaş altındaki olgulardan yüksek olması istatistiksel olarak anlamlı bulunmuştur ( $\mathrm{p}<0,05)$. Olguların yaşlarına göre hemodiyaliz maliyetleri arasında istatistiksel olarak anlamlı farklılık saptanmamıştır ( $\mathrm{p}>0,05)$ (Tablo 7).

Tablo 7: Yaşa Göre Birimlere İlişkin Maliyetin Değerlendirilmesi

\begin{tabular}{|c|c|c|c|}
\hline & \multicolumn{2}{|c|}{ Yaş (yll) } & \multirow[b]{3}{*}{$\boldsymbol{p}$} \\
\hline & < 65 yaş $(n=355)$ & $\geq 65$ yaş $(n=452)$ & \\
\hline & Ort \pm SS (Medyan) & Ort \pm SS (Medyan) & \\
\hline Biyokimya laboratuvarı & $235,8 \pm 184,2(198,8)$ & $256,3 \pm 165,1(225,2)$ & $0,004 * *$ \\
\hline Eczane & $192,2 \pm 270,5(92,7)$ & $293,3 \pm 602,4(158)$ & $0,001 * *$ \\
\hline Genel müdahaleler & $80,9 \pm 89,5(51,7)$ & $113,0 \pm 143,5(71,8)$ & $\boldsymbol{O}, \boldsymbol{O O O 1} 1^{* *}$ \\
\hline Hematoloji- onkoloji- kemoterapi & $47,8 \pm 167,1(0)$ & $81,7 \pm 350,0(0)$ & $0,015^{*}$ \\
\hline Refakat ücretleri & $28,2 \pm 37,5(10)$ & $34,1 \pm 37,8(30)$ & $0,009^{* *}$ \\
\hline Hemodiyaliz & $117,9 \pm 279,0(0)$ & $127,3 \pm 282, \mathrm{o}(\mathrm{o})$ & 0,224 \\
\hline Yatak ücretleri & $194,9 \pm 192,7(150)$ & $207,6 \pm 171,4(180)$ & $\boldsymbol{o , o 3 3} *$ \\
\hline
\end{tabular}


Cinsiyete göre birimlere ilişkin maliyetin değerlendirilmesi yapıldı̆̆ında; olguların cinsiyetlerine göre biyokimya laboratuvarı, eczane, hematoloji-onkoloji-kemoterapi, refakat ücretleri ve yatak ücretleri istatistiksel olarak anlamlı farklılık göstermemektedir (p>0,05) (Tablo 8).

Erkek olgularda genel müdahaleler ve hemodiyaliz ( $\mathrm{p}=0,026)$ maliyetlerinin, kadınlardan yüksek olması istatistiksel olarak anlamlı bulunmuştur ( $\mathrm{p}<0,05$ ) (Tablo 8).

Tablo 8: Cinsiyete Göre Göre Birimlere İlişkin Maliyetin Değerlendirilmesi

\begin{tabular}{llll}
\hline & & \multicolumn{2}{c}{ Cinsiyet } \\
& Kadın (n=421) & Erkek (n=386) & \\
& Ort \pm SS (Medyan) & Ort \pm SS (Medyan) & $\boldsymbol{p}$ \\
\hline Biyokimya laboratuvarı & $249,6 \pm 187,2(215,5)$ & $244,8 \pm 158,5(213,6)$ & $\boldsymbol{o , 8 3 8}$ \\
Eczane & $223,6 \pm 312,9(133)$ & $276,4 \pm 624,0(136)$ & $\boldsymbol{o , 5 8 2}$ \\
Genel müdahaleler & $94,9 \pm 113,5(57,1)$ & $103,1 \pm 133,9(69)$ & $\boldsymbol{o , o 4 1}$ \\
Hematoloji-onkoloji-kemoterapi & $74,2 \pm 318,8(0)$ & $58,7 \pm 242,5(0)$ & $\boldsymbol{o , 7 3 6}$ \\
Refakat ücretleri & $31,0 \pm 37,5(20)$ & $32,1 \pm 38,0(30)$ & $\boldsymbol{o , 6 3 1}$ \\
Hemodiyaliz & $101,2 \pm 251,7(0)$ & $147,1 \pm 307,5(0)$ & $\boldsymbol{o , o 2 6} *$ \\
Yatak ücretleri & $206,7 \pm 190,0(180)$ & $196,8 \pm 171,0(150)$ & $\boldsymbol{o , 5 4 7}$ \\
\hline Mann Whitney UTest & $* 0<, 05$ & &
\end{tabular}

\section{Tartışma}

Prevalansı hızla artan bir hastalık olan Diyabetes Mellitüs varlığında; kardiyovasküler, serebrovasküler hastalık, periferik arter hastalı̆̆ı ve mikrovasküler komplikasyonların eşlik etmesi hastalarda morbidite ve mortalite artışı dışında, tedavi masraflarının, yapılan analizlerin (görüntüleme teknikleri ve laboratuvar testleri gibi) ve hospitalizasyon sıklığının artmasına neden olmaktadır. Yapılan çalışmalar sonucunda; diyabetli hastalarda gelişebilen periferik vasküler hastalık ve periferik nöropati sonucu nontravmatik alt ekstremite ampütasyonunun, hospitalizasyonun \%25’inden sorumlu olduğu görülmüştür ${ }^{6,7}$. 
Tedavi maliyeti yüksek olan son dönem böbrek hastalığının etiyolojisinde de \%40 oranla diyabetin en sık neden olduğu tespit edilmiştir ${ }^{8,9}$.

Amerika Birleşik Devletlerinde (ABD) 2012 yılında yapılan geniş çaplı araştırmada; diyabetik hastalar için yapılan hemşire bakımı, doktor kontrolleri, acil servise hastaların başvuruları ve insülin dâhil diğer medikal tedavi harcamalarının, tüm harcamaların yarısını oluşturduğu ve özellikle 65 yaş ve üzeri diyabetli hastalarda giderlerin daha yüksek olduğu saptanmıştırio. Bu çalışmada 65 yaş ve üzeri hastalarda tanı ve tedavi için yapılan harcamaların 65 yaş ve altındaki hastalara kıyasla daha yüksek oranda olduğu saptanmıştır (Tablo 4).

Hasta yaşı ile Diyabetes Mellitüs giderleri arasında pozitif korelasyon mevcuttur. $\mathrm{Bu}$ pozitif korelasyon; hastalığın süresine bağlı olarak komplikasyon sıklığının artışı ile açıklanabilir. ABD'de yapılan aynı çalışmada 2007-2012 arası veriler değerlendirildiğinde; Diyabetes Mellitüslü hastalar arasında komplikasyonlara bağlı (kardiyovasküler hastalık, renal komplikasyonlar vb.) hospitalizasyon oranı \%40 bulunmuştur. Bu çalışmada ise; 65 yaş altı hastalarda hospitalizyon oranı \%44 olarak saptanmışken; 65 yaş üstü hastalarda bu oran \%56'ya ulaşmıştır.

ABD’ de yapılan çalışmada; Diyabetes Mellitüs hastaları için yapılan toplam giderlerin \%57’sinin medikal harcamalar, \%23'ünün hasta bakımı ve \%17’sinin analizler için harcandığı görülmüştür. Bu çalışmada ise İç Hastalıkları Kliniğı̈’ne yatışı yapılan diyabetik hastalar için harcamaların en önemli kısmını medikal tedavi, biyokimyasal tetkikler, hospitalizasyon giderleri, hemodiyaliz oluştururken hasta muayene ücretlerinin daha geri planda kaldığı görülmüştür ${ }^{11}$.

807 hastanın yer aldığı bu çalışmada diyabetli bir hastanın ortalama yatış maliyetinin $1.269,81 \pm 1.331,96$ TL olduğu görülmüştür. Maliyet analizine göre 27 birime ayrılan değerlendirmede ortalama maliyette en fazla yer alan birimler içerisinde sırasıyla;

Eczane (hastaların \%95,9) 248,8 $\pm 487,6$ TL [\$270,5];

Biyokimya laboratuvarı (hastaların \%99,5) 247,3ะ174,o TL [\$137,4];

Yatak ücreti (hastaların \% 95,4) 211,7 $\pm 179,8$ TL $[\$ 117,6]$;

Hemodiyaliz (hastaların \% 24,7) 123,2 $\pm 280,6$ TL [\$155,5]; 


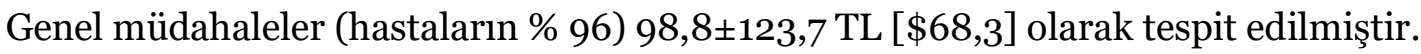
Toplam hasta sayısının hemodiyaliz hizmeti alan hasta sayısına $(\mathrm{n}=199)$ oranının \% 24,7 olmasına rağmen maliyete olan etkisinin belirgin bir şekilde yüksek olduğu tespit edilmiştir. Hemodiyaliz hizmeti alan hastaların ortalama hemodiyaliz maliyeti $499,5 \pm 362,7$ TL $[\$ 277,8]$ olması ile alt birimlerin içerisinde en maliyetli birim olduğu görülmüştür.

Muayene ücreti genel ortalamada 5,8 $\pm 10,8 \mathrm{TL}$ iken, muayene ücreti hizmeti faturalandırılan 349 hastada (hastaların \% 43,2'si) ise 13,3 $\pm 13,0$ TL olup toplam maliyete etkisinin önemsenmeyecek düzeyde olduğu görülmüştür. Ortalama muayene ücretinin (hekim vizitlerinin) düşük olması muayene ücretlerinin yeterince faturalandırılmadığını düşündürse de bu hizmeti alan (veya faturalandırılması yapılan) hastalarda da ortalama muayene ücretinin düşük saptanması muayene ücretlerinin düşük olduğunu göstermiştir.

Bu çalışmada; harcamaların en büyük bölümünü medikal tedaviler, laboratuvar testleri, yatak ücreti ve hemodiyalizin oluşturduğunu tespit edilmiştir. Her iki çalışmada maliyetlere en çok katkıda bulunan komplikasyonlar farklı olsa da ortak nokta olarak diyabetin komplikasyonlarının toplam maliyetteki payının azımsanmayacak düzeyde olmasidır.

$\mathrm{Bu}$ çalışmada hastaneye yatırılmış diyabetli hastalardaki maliyetlerin alt grup analizi yapıldığında en çok maliyetin sırasıyla; medikal harcamalar, laboratuvar testleri, yatak ücreti, hemodiyaliz ve genel müdahaleler olduğu görülmüştür.

\section{Sonuç}

Diyabetes mellitüs tanısı olan hastaların maliyet analizlerini araştıran çalışmalarda farklı veriler elde edilmesine rağmen bu çalışmalarda diyabetin komplikasyonlarının giderler dağılımında önemli yer tuttuğu görülmüsstür. Maliyet ile ilgili yapılan çalışmalardaki giderler değerlendirildiğinde; doktor tarafından düzenli takip ve tedavinin komplikasyon ve maliyet üzerindeki önemi kanıtlanmıştır. Düzenli takip ve tedavi edilen hastalarda; laboratuvar testleri, görüntüleme teknikleri ve gelişen komplikasyonları tedavi etmek için harcanan giderlerin daha düşük olduğu görülmüştür. $\mathrm{Bu}$ çalışmanın sonucunda hekim vizitinin maliyetinin düşük; ilaç 
harcamaları, laboratuvar tetkikleri, yatak ücretleri ve hemodiyaliz hizmetinin maliyetli olmasından dolayı, hastaların hastalık ve komplikasyonları hakkında daha fazla bilgilendirilmesinin önemi görülmektedir. Ülkemizde, hastalara sunulan koruyucu hekimlik ve bakım hizmetlerinin arttırılması ile Diyabetes Mellitüs tanılı hastalarda morbidite-mortalite oranının azalması ile giderlerin azaltılması sağlanabilir. Bu durumun halk sağlı̆̆ına ekonomik açıdan önemli katkı sağlayabileceği kanaatindeyiz.

\section{KAYNAKLAR}

1. Beyhun N, Ercümen Ç. Hastalık maliyeti ve astım. Tüberküloz ve Toraks Dergisi. 2004;52(4):386-392.

2. Kolsuz M. Hastaneye yatarak veya yoğun bakımda tedavi görmesi gereken toplum kökenli pnömonilerde hastanede yatış süresini etkileyen faktörler ve maliyet. Solunum Hastahklarn Derg. 2001;12:1-7.

3. Aktaş İ. Yatarak fizyoterapi alan hastaların yaşam kaliteleri ve maliyet analizi. Marmara Medical Journal. 2013;26:1-4.

4. Balçık P, Şahin B. Sağlık hizmetlerinde maliyet etkililik analizi ve karar analizi. Hacettepe Sağllk İdaresi Dergisi. 2013;16(2):121-134.

5. Satman I. Twelve-year trends in the prevalence and risk factors of diabetes and prediabetes in Turkish adults. European Journal of Epidemiology. 2013;28(2):169-180.

6. Cea-Calvol L, Conthe P, Gomez-Fernandez, et al. Target organ damage and cardiovascular complications in patients with hypertension and type 2 diabetes in Spain: a cross-sectional study. Cardiovasc Diabetol. 2006;23(5):15-16.

7. Al-Maskari F, El-Sadig M, Norman J. The prevalence of macrovascular complications among diabetic patients in the United Arab Emirates. Cardiovascular Diabetology. 2007;6:24-26.

8. US Renal Data System: USRDS Annual Data Report: Volume One: Chronic Kidney Disease in the United States 2014.chapter 9:cost of ESRD;1-3. 
9. Soll O, Jenssen T, Kristiansen I. Diabetes: cost of illness in Norway. BMC Endocrine Disorders. 2010;10(1):15.

10. American Diabetes Association. Economic costs of diabetes in the US in 2012. Diabetes Care. 2013;36(4):1033-1046.

11. Charmaine S, Huyu N, Matthias Paul Han, et al. Direct Medical Cost of Type 2 Diabetes in Singapore. PLOS ONE. 2015;10(3):14-18. 